\title{
Notes and News
}

\section{Grant to the International African Institute from the Ford Foundation, New York}

Members of the Institute will know, from the Administrative Director's Report to the Executive Council at its meeting in 1953, that the Institute's financial position had been causing some anxiety. Although the growing interest in African studies, as well as developments in Africa itself, were presenting many opportunities for the expansion of the Institute's activities, rising costs coupled with a stationary or falling income were threatening not only to prevent expansion but to enforce a restriction of its work.

Fortunately, however, as was reported in the July issue of this journal, the efforts of members of the Council have secured a number of valuable contributions from various sources-in particular from the Phelps-Stokes Fund, the Carnegie Corporation of New York, and a number of British and Belgian firms.

Still more recently the Ford Foundation of New York has made a most generous response to representations put forward on behalf of the Institute. On the basis of a lengthy report on the various activities and needs of the Institute, submitted by the Director, and the recommendations made by Professor W. O. Brown following his study of our activities last year, the Ford Foundation has allocated a grant of $\$ 50,000$, expendable over a period of approximately two years. It is to be devoted in part to maintaining the Institute's library, bibliographical and information services, and African Abstracts, and in part to organizing and financing field research in Africa.

This award is doubly welcome, not only as valuable material assistance, but as evidence of interest in and recognition of our work on the part of the Ford Foundation. Members of the Institute will, we are sure, be glad to know of this good fortune and will join with the Council and Officers in gratitude to our American friends for their generous and timely assistance.

\section{International Research Office on the Social Implications of Technological Change}

A sEMINAR was held in Paris in March 1954 at which experts in various disciplines (ethnology, sociology, economics, psychology, \&c.) discussed economic motivations and incentives in traditional and modern environments in the context of 'underdeveloped' countries. The theme of the seminar was chosen with both theoretical and practical aims in view, viz. to make a contribution to the study of economic motivations, and to assist towards the solving of urgent problems attending the economic development of underdeveloped countries.

Specific subjects studied included the definition and comparison of customary or traditional and non-traditional environments; the nature of traditional techniques; attitudes to work and incentives to economic activity; relations between subsistence economy and market economy; the nature of rural economies and the effects of 'modernizing' factors; the rural exodus and the lack of balance between urban and rural areas; influences exercised by industrial undertakings, adaptation to new professions, effects of non-traditional environment on behaviour and social relationships, and the present state of research on these topics.

At the conclusion of the seminar the trends of the discussions were summed up by the Chairman, Professor Raymond Firth, who suggested that, in spite of differences of approach by various disciplines, most studies were in fact progressing by very similar methods, and through the variety of descriptive material presented it had been possible to arrive at a clearer definition of the problem of economic motivation. The fundamental question was the possibility of the emergence of a new motivations equilibrium adapted to the needs of 